\title{
Investigation for the Identification of Transient Amplifying/Stem Cell Pool in Oral Mucosa
}

\author{
A Thesis \\ Presented in Partial Fulfillment of the Requirements for \\ The Degree Master of Science in the \\ Graduate School of The Ohio State University \\ By \\ Marvin Frank Jabero, D.D.S. \\ $* * * * *$
}

The Ohio State University

2010

Master’s Examination Committee:

Dr. Susan R. Mallery, Adviser

Approved by

Dr. Erik W. Evans

Dr. Henry W. Fields

Adviser

Graduate Program in Dentistry 
Copyright by

Marvin Frank Jabero

2010 


\begin{abstract}
Statement: To date, no studies have been conducted to definitely identify stem cells or transient amplifying (TA) cells that reside in the oral cavity. Stem cell division creates two cell types, a memory daughter cell and a transient amplifying cell. TA cells, which are slightly more differentiated than stem cells, serve as a reservoir for wound healing and homeostasis. Identification of either the stem cell or TA cell location(s) will provide a better understanding of normal and abnormal epithelial growth and tissue regeneration in the oral cavity.

Epidermal stem cells are located within the bulge zone of the associated hair follicles and not within the basal cell layer of the overlying epidermis. Skin wounds induce increased mitotic activity of bulge cells during wound repair. As the minor salivary glands of the oral mucosa represent an analogous specialized epithelial site, one of the stem cell pools of the oral mucosa may reside within salivary gland acini.
\end{abstract}

Study Aim: The purpose of this study was to determine the location(s) of the oral mucosal stem cell pool(s).

Materials and Methods: To address this question, we employed: 1) a murine oral mucosal wound healing model (wounding initiates stem cell proliferation), 2) human oral mucosal biopsies of ulcers overlying minor salivary glands. Immunohistochemical 
markers employed were: 1) K15 (primitive keratinocytes), 2) BrdU (thymidine analogue indicative of DNA synthesis), 3) CD34 (a putative epidermal stem cell marker), 4) CD133 (hematopoietic and general stem markers).

Results: Initial studies of ulcerated mucoceles demonstrated K15 positive staining tracking along the salivary gland excretory and merging with the associated basal cell layer of the epithelium. These findings prompted the murine studies that entailed palatal wounding. BrdU in vivo labeling, and timed animal sacrifices to monitor progression of the BrdU stained cells recruited to re-epithelialize the wound. Results of these murine studies showed: 1) BrdU stained cells were detected in both the basal cell layer of the intact epithelium adjacent to the wound as well within underlying salivary gland acini and associated ducts, 2) as time post wounding increased, BrdU positivity was indentified in excretory ducts merging with the overlying basal epithelial cells, 3) K15 positivity was distributed in the majority of basal layer epithelial cells and the peripheral portion of the excretory salivary gland ducts, 4) control mice demonstrated negligible BrdU labeling, which was restricted to the basal layer epithelial cells. Our results confirm that CD34 is not stem cell specific in oral mucosa, as this antibody stained mast cells in the underlying connective tissues. Ongoing studies with more stem cell specific antibodies (CD133) are promising and have indicated focal, punctate positivity within few acinar and basal layer epithelial cells. . 
Conclusions: These data imply that selected salivary gland acini are comparable to the bulge zone of the hair follicle and these cells contribute to the oral mucosal stem cell pool. Further, the localization of either of these cell pools may lead to advancements in cancer treatment and help direct chemoprevention. 


\section{Dedicated to}

My wife, parents and siblings

Thank you for your unconditional love and support. 


\section{ACKNOWLEDGMENTS}

I would like to express my deepest appreciation to my committee advisor, Dr. Susan Mallery, who has been an outstanding teacher and friend. She continually strives for excellence and poses a teaching quality that only a few can achieve. Her patience, intelligence and dedication to research infiltrate everyone in her lab. Without her guidance and persistent help this project would not have been possible.

I would like to thank my committee members Dr. Erik W. Evans and Dr. Henry Fields for their support and assistance with this project.

A special thanks to the current and previous faculty within our expanded department for their continual support and hard work. I could not ask for better teachers who always made themselves available and pushed me to be the best resident possible. 


\section{VITA}

October 12, 1979............................Born Flint, Michigan.

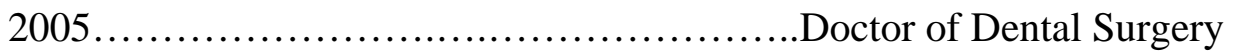

The University of Michigan

2005-present.............................. Oral and Maxillofacial Surgery Resident The Ohio State University

Columbus, Ohio

\section{PUBLICATIONS}

1. Chacon, GE, Ugalde, CM, Jabero, MF. Genetic disorders and bone affecting the craniofacial skeleton. Oral Maxillofac Surg Clin North Am 2007;19(4):467-74, v.

2. Jabero M, Sarment D. Advanced surgical guidance technology: a review. Implant Dent. 2006; 15(2): 135

3. Magliocca K, Jabero M, Alto D, Magliocca J. Knowledge, beliefs, and attitudes of dental and dental hygiene students toward obesity. J.Dent.Educ. 2005; 69(12): 1332

\section{FIELDS OF STUDY}

Major field: Dentistry

Specialization: Oral and Maxillofacial Surgery 


\section{TABLE OF CONTENTS}

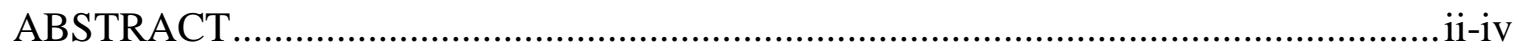

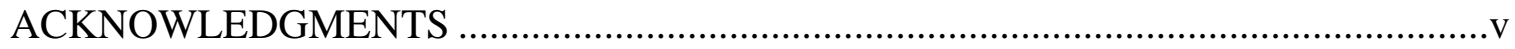

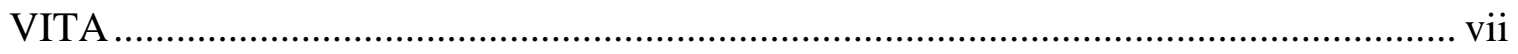

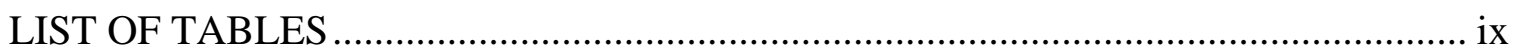

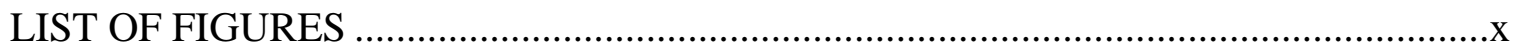

CHAPTER 1: INTRODUCTION ....................................................................... 1-6

CHAPTER 2: MATERIALS AND METHODS ……………………………………... 7-14

CHAPTER 3: MANUSCRIPT ……………………………………………... 15-32

CHAPTER 4: CONCLUSION …………………………..........................................33

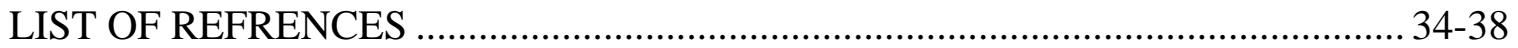




\section{LIST OF TABLES}

Table 1: Murine Protocol........................................................9

Table 2: Image Pro Comparison of BrdU andK15..................................29 


\section{LIST OF FIGURES}

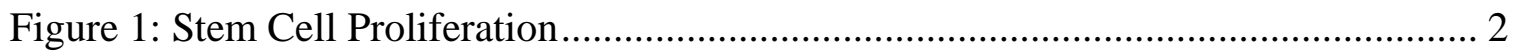

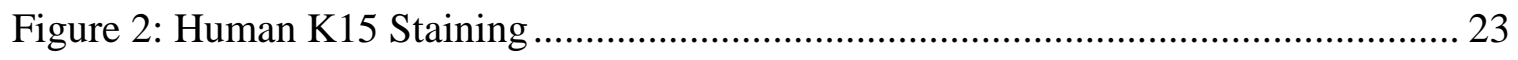

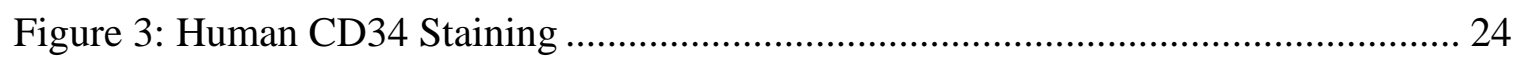

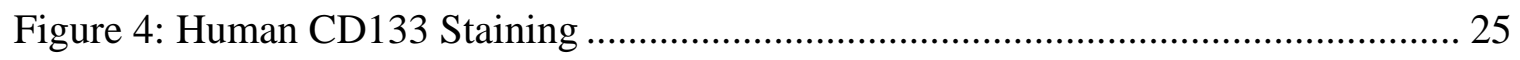

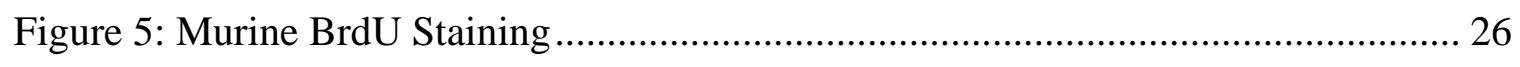

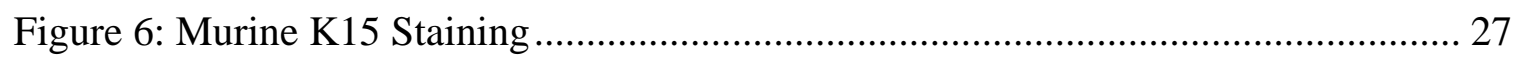

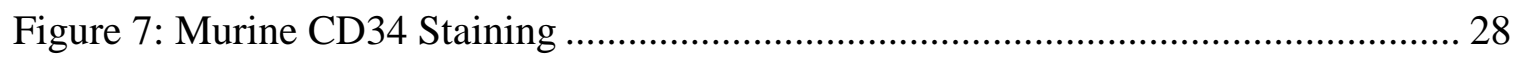




\section{Chapter 1}

\section{Introduction}

\section{Stem Cell Overview}

Stem cells are the progenitor cells for every cell in our body. They are considered an “immature" or undifferentiated cell that can mature or differentiate into various types of tissues. Most are familiar with embryonic stem cells from fertilized eggs of humans. There are, however, pools of stem cells in various anatomic locations known as "adult" stem cells that help maintain the integrity of the integumentary, skeletal and vascular tissues. ${ }^{1}$ For example, hematopoietic cells located in bone marrow give rise to the entire blood cell lineage. Stem cell division creates two cell types, a memory daughter cell and a transient amplifying cell (TA). It is well established that epithelial stem cells in selfrenewing tissue contain TA cells that serve as an important reservoir for wound healing

and homeostasis. ${ }^{2,3}$ These cells are the first descendents in the cell growth hierarchy and are only slightly more differentiated than stem cells (figure 1). 
Figure 1: Stem Cell Proliferation

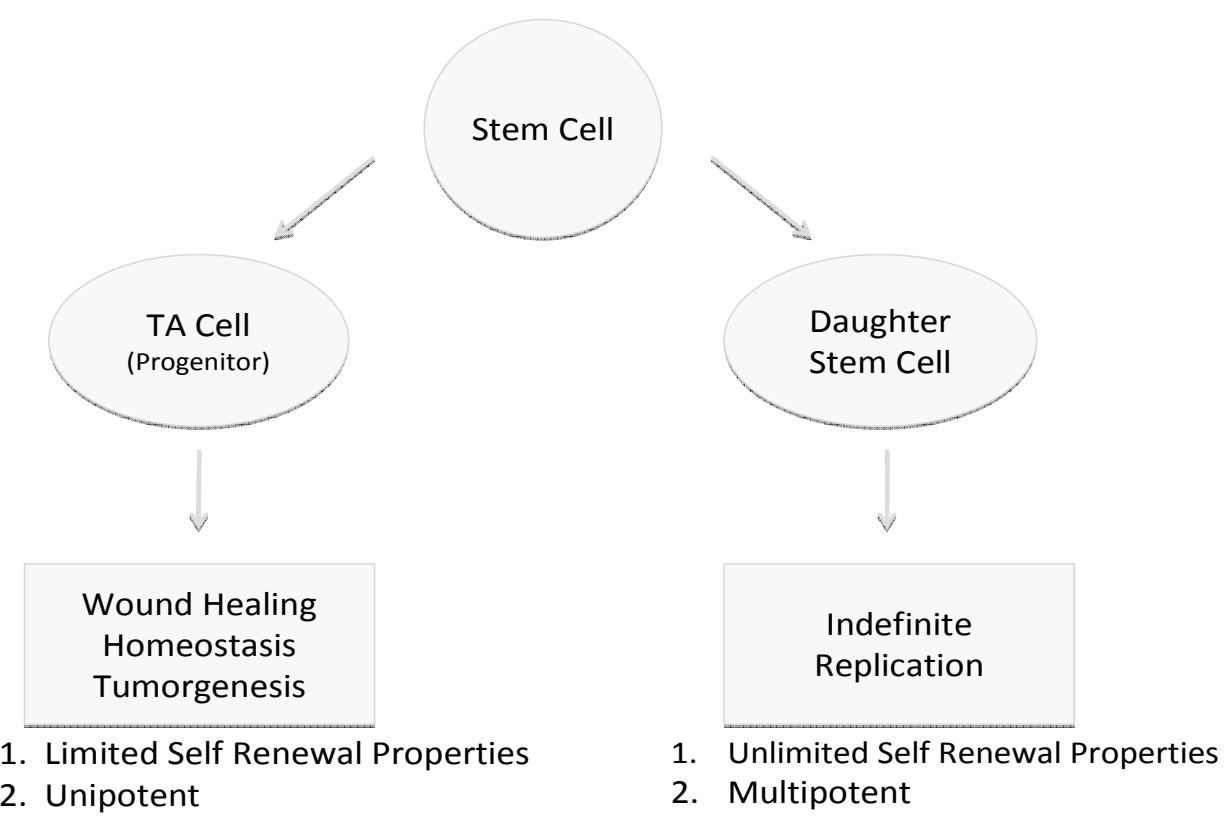

\section{Transient Amplifying Cells and Oral Mucosa}

To date, no studies have been conducted to identify stem cells or TA cells that reside in the oral cavity. Identification of either the stem cell or TA cell location(s) will provide a better understanding of normal and abnormal epithelial growth including tissue regeneration in the oral cavity. Oral mucosa is a very unique and dynamic tissue that is under constant environmental stresses that often requires rapid turnover of epithelium and connective tissue. Literature suggests that oral epithelial stem cells are fully capable of continuously regenerating during their lifetime but fail to distinguish stem cells from other basal cells. ${ }^{4}$ Furthermore, the location and activity of stem cells in oral premalignant and malignant epithelial disease has not been clarified in the literature. Epithelial dysplastic lesions also referred to as "pre-cancerous" lesions undergo alterations in the TA cell pool that potentially leads to sustained abnormal growth of 
tissue. ${ }^{5-9}$ When dysplastic lesions are surgically excised with microscopically tumor free borders, the lesion may still recur up to $30 \%$ of the time. ${ }^{10,11}$ This evidence leads us to speculate that oral epithelial premalignant and malignant lesions arise as a consequence of altered stem cells and/or TA cells. ${ }^{12}$ This correlates with the previous discussion of skin tumors arising from epithelial TA cells. The ability to target these TA and stem cell pools can direct targeted oral chemoprevenetive strategies.

\section{Stem cells and previous studies}

There have been recent breakthroughs in stem cell research during the past decade that created many avenues for scientists and clinicians to better understand and apply gene therapy for human diseases. One of the major stem cell related discoveries was the identification of epidermal precursor stem cells (TA cells). These cells are not just located within the basal cell layer of the overlying epidermis, but more specifically reside within the bulge zone of the underlying associated hair follicles. ${ }^{13-16}$ The use of immunohistochemistry in both human and murine models established advancements for epidermal stem cell research. The use of keratin promoter markers K5, K-14 and K-15 has provided researchers information regarding cellular homeostasis, development, wound healing and carcinogenesis with respect to the integumentary system. ${ }^{17-23}$

Epidermal stem cells are located within the bulge zone of the associated hair follicles and not within the basal cell layer of the overlying epidermis. ${ }^{13-15}$ While it is generally accepted that the oral mucosal stem cells reside within the basal cell layer, due to ethical concerns regarding cell labeling, these findings have not been substantiated in humans. Skin wounds induce increased mitotic activity of bulge cells during wound repair. The 
minor salivary glands of the oral mucosa represent an analogous structure to the bulge zone of the hair follicle indicating activity within the salivary gland acini.

\section{Bromodeoxyuridine}

Bromodeoxyuridine (5-bromo-2-deoxyuridine, BrdU) is a synthetic nucleoside that is an analogue of thymidine. BrdU is commonly used in the detection of proliferating cells in living tissues. Incorporation of BrdU occurs during the S-phase of DNA synthesis and substitutes uridine for thymidine during replication. Consequently, BrdU is employed to detect actively replicating cells during DNA synthesis. Due to its ability to create DNA mutations, it's use is contraindicated in human subjects.

\section{Keratin 15}

Keratin 15 belongs to a superfamily of intermediate filamentous proteins. This filament composes part of the cytoskeleton comprised of 10-nm-diameter filaments and is largely found in stratified epithelium. This marker is most commonly expressed in stable and slowly replicating basal cell layer of skin and other tissues. ${ }^{13-16,24}$

\section{Clusters of Differentiation}

Clusters of differentiation, routinely abbreviated as CD, are various types of molecules such as receptors or ligands used to identify specific cell surface molecules that are defined by a certain set of monoclonal antibodies. ${ }^{25}$ These protocols were introduced in 1982 and more than 300 types have been developed. ${ }^{26}$ CD types are listed numerically based on discovery time. For example, CD34 was discovered before CD133. These proteins can help identify an array of cell types such as lipids, lymphocytes, leukocytes, stem cells and many others. ${ }^{27}$ 


\section{CD34}

The CD34 molecule is a glycoprotein, according to the Online Mendelian Inheritance in Mandatabase (OMIM), with a "molecular mass of approximately $110 \mathrm{kD}$ that is selectively expressed on human hematopoietic progenitor cells”. Human tissues that stain for CD34 include:

- Hematopoietic progenitor bone marrow stem cells ${ }^{28}$

- $\quad$ Mast cell adhesion ${ }^{29}$

- Dendritic cells ${ }^{30}$

- Cutaneous tumors ${ }^{31}$

- Embryonic fibroblasts ${ }^{32}$

- Corneal keratocyets ${ }^{33}$

\section{CD133}

CD 133 (prominin-1) was the first developed surface protein containing a five transmembrane domain and is known to many as the "molecule of the moment." 34 This protein has been associated as a marker for isolating primitive hematopoietic, neural and cancer stem cells. ${ }^{35-37}$ Prominin-1 expression has also been demonstrated in cancerous epithelial tissue, pancreatic ductal tissue, and many other tissue and physiological systems. $^{38-40}$

\section{CD135 (FLT3 Ligand)}

According to the national library of medicine, CD 135 is receptor tyrosine kinase involved in hematopoesis. It is closely related to FMS proto-oncogene protein and is commonly mutated in acute myeloid leukemia. ${ }^{41}$ CD 135 has been identified as a surface marker in multipotent and common lymphoid progenitors in bone marrow. ${ }^{42,43}$ 


\section{Current Concepts in Stem Cell Therapy}

Stem cell therapy is currently focused towards treatment of many diseases with

underlying genetic perturbations and bone marrow derived disease processes. ${ }^{44}$ These disease and diagnostic indications include:

- Parkinson's disease ${ }^{45,46}$

- Alzheimer diagnosis from bone marrow derived cells ${ }^{47}$

- Bone marrow derived gastric cancer ${ }^{48}$

- Kidney transplant associated skin carcinoma ${ }^{49}$

- Leukemia diagnosis with CD135 ${ }^{41}$

- Isolation of progenitor cells in renal tissues ${ }^{50}$

\section{Specific Aim}

The purpose of this study was to determine the location(s) of the oral mucosal stem cell pool(s) using a murine model and concurrent human oral tissue evaluation..

\section{Experimental Hypothesis}

The acinar structures of the minor salivary glands harbor oral mucosal stem cells.

\section{Null Hypothesis}

The exclusive contributing cell to surface oral epithelium resides within the basal layer keratinocytes. 


\section{Chapter 2}

\section{Materials and Methods}

\section{Human Tissue Selection}

We obtained ulcerated and intact human oral mucosal specimens from archived tissue from The Ohio State University Oral Pathology service. This study was in accordance with The Ohio State University Institutional Review Board (protocol \#2007E0437). Tissue specimens were selected based on abundance of minor salivary glands and presence of terminal salivary duct surface epithelium interface. Tissue procured was then analyzed using multiple stem cell markers.

\section{Murine Tissue Selection}

Animal procedures were conducted in accordance with The Ohio State University Institutional Animal Care and Use Committee (IACUC). Authorization was approved and accepted on September $13^{\text {th }} 2006$ (Protocol \#2006A0174).

Our first goal was to determine the region of murine oral mucosa with the highest concentration of minor salivary glands. Three FVB mice heads from another study was used to biopsy selected oral cavity sites. Biopsies of the soft/hard palate, ventral tongue, buccal mucosa and floor of the mouth underwent tissue processing and light microscopic evaluation to determine which area contained the highest number of minor salivary glands. 


\section{Murine Model}

This model involved fifteen eight week old male FVB mice, with a six day experimental period. All mice were provided water and food access ad libitum and housed under a 12hour dark and 12-hour light cycle. The fifteen mice were randomly assigned in two separate groups, i.e. ten in the experimental group and five in the control group. On day one, the experimental group was anesthetized by intraperitoneal injection (IP) of ketamine (40mg/kg) and Xylazine (10mg/kg). Once appropriate anesthesia was obtained, the experimental group was wounded. An experienced oral and maxillofacial surgeon using a dental implant drill performed the wounding. The tissue was wounded at the soft palate, slightly to the right of the midline and posterior to the vibrating line. Each wound was approximately $3 \times 3 \mathrm{~mm}$ in size. Next, all mice were injected with BrdU (50mg/kg IP at a concentration of $10 \mathrm{mg} / \mathrm{ml}$ in $0.9 \% \mathrm{NaCl}$ ).

The following day (day 2), all mice were injected with the same dose and concentration of BrdU. Three hours later, three mice (two experimental and one control) were euthanized and tissue samples were obtained as will be described. On day three, the remaining 12 mice will be injected with a third dose of BrdU and three more mice (two experimental and one control) will be euthanized and tissue sampled. This process will continued with all remaining mice receiving BrdU injections daily until euthanized (table $1)$. 


\begin{tabular}{|c|c|c|c|c|c|c|c|}
\hline Mouse & 0 & 24 & 48 & 72 & 96 & 120 & \multirow{6}{*}{$\begin{array}{l}\text { Legends: } \\
\text { Brdu: Mouse injected with } \\
50 \mathrm{mg} / \mathrm{kg}\end{array}$} \\
\hline 1 & $w$ & EUTH & & & & & \\
\hline 2 & W & BrdU & EUTH & & & & \\
\hline 3 & W & BrdU & BrdU & EUTH & & & \\
\hline 4 & $w$ & BrdU & BrdU & BrdU & EUTH & & \\
\hline 5 & W & BrdU & BrdU & BrdU & BrdU & EUTH & \\
\hline 6 & $w$ & EUTH & & & & & \multirow{2}{*}{$\begin{array}{l}\text { Euth: Mouse euthanized } \\
\text { with Halothane }\end{array}$} \\
\hline 7 & $w$ & BrdU & EUTH & & & & \\
\hline 8 & W & BrdU & BrdU & EUTH & & & \multirow{3}{*}{$\begin{array}{l}\text { Mice } 1-10(W) \text { : } \\
\text { soft/hard palate wounded } \\
\text { with dental implant drill }\end{array}$} \\
\hline 9 & $w$ & BrdU & BrdU & BrdU & EUTH & & \\
\hline 10 & $w$ & BrdU & BrdU & BrdU & BrdU & EUTH & \\
\hline 11 & C & EUTH & & & & & \multirow{5}{*}{$\begin{array}{l}\text { Mice } 11-15(C) \\
\text { non-wounded control group }\end{array}$} \\
\hline 12 & C & BrdU & EUTH & & & & \\
\hline 13 & C & BrdU & BrdU & EUTH & & & \\
\hline 14 & C & BrdU & BrdU & BrdU & EUTH & & \\
\hline 15 & C & BrdU & BrdU & BrdU & BrdU & EUTH & \\
\hline
\end{tabular}

\section{Euthanizing protocol}

The mice were anaesthetized as previously described. Once anesthesia has taken affect, the mice were placed in a 5 percent halothane chamber. Once asleep, the mice were euthanized by cervical dislocation. Death was confirmed by lack of cardiac function. The palatal tissues were then dissected from the euthanized mice and immediately placed in formalin for tissue processing and experimental analysis.

\section{Murine Anti-BrdU Immunohistochemistry Staining}

Paraffin sections were heated in a $56^{\circ} \mathrm{C}$ oven for 90 minutes prior to hydration.

Deparaffinization and hydration was accomplished with histoclear, ethanol and distilled water. Endogenous peroxides were quenched using 3\% hydrogen peroxide in methanol. Samples were treated with trypsin (antigen masking) and incubated at $37^{\circ} \mathrm{C}$ for 30 
minutes. Next, samples were blocked for 90 minutes with 5\% normal horse serum, $1 \%$ BSA, 0.05\% Tween 20 in PBS. Sections were then incubated at $4^{\circ} \mathrm{C}$ overnight with primary antibody anti-brdu VECTOR, cat VP-B209 with a dilution of 1:200. Slides were then Incubated 1 hour with $7.5 \mu \mathrm{g} / \mathrm{ml}$ biotinylated secondary antibody solution (1:200 dilution) at RT (Horse anti-mouse IgG $(\mathrm{H}+\mathrm{L})$ ). Slides were then treated for 30 minutes with VECTASTAIN ABC followed by DAB (Vector, cat\# SK-4100) staining for 5 minutes then counterstained with Hematoxylin QS for 1 minute. Lastly, slides were dehydrated and cleared for visual inspection.

\section{Murine Anti-K15 immunohistochemistry with VIP}

Prepared paraffin sections were heated in a $56^{\circ} \mathrm{C}$ oven for 90 minutes prior to hydration. Deparaffinization and hydration was accomplished with histoclear, ethanol and distilled water. Endogenous peroxides were quenched using $3 \%$ hydrogen peroxide in methanol. Samples were then treated with antigen retrieval using a 10mM Citrate buffer by heating samples for 7 minutes in a microwave, followed by a 20 minute room air cooling. Next, samples were blocked for 60 minutes with 5\% normal goat serum, 1\% BSA, 0.05\% Tween 20 in PBS. Sections were then incubated at $4^{\circ} \mathrm{C}$ overnight with primary chicken anti-K15 polyclonal antibody (from COVANCE, cat\# PCK-153P, stored at $-20^{\circ} \mathrm{C}$ ). Next, slides were incubated for 1 hour with $7.5 \mu \mathrm{g} / \mathrm{ml}$ biotinylated secondary antibody solution (1:200 dilution) at RT (Goat anti-Chicken IgG (H+L), 1.5mg/ml from VECTOR). Slides were then treated for 30 minutes with VECTASTAIN ABC followed by VIP staining. Counterstaining was preformed with pre-heated methyl green for 5 minutes. Lastly, slides were dehydrated and cleared for visual inspection. 


\section{Murine CD34 Immunohistochemistry with VIP}

Prepared paraffin sections were heated in a $56^{\circ} \mathrm{C}$ oven for 90 minutes prior to hydration. Deparaffinization and hydration was accomplished with histoclear, ethanol and distilled water. Endogenous peroxides were quenched using 3\% hydrogen peroxide in methanol. Samples were then treated with antigen retrieval using a $10 \mathrm{mM}$ Citrate buffer by heating samples for 7 minutes in a microwave, followed by a 20 minute room air cooling. Next, samples were blocked for 60 minutes with 5\% normal rabbit serum, 1\% BSA, 0.05\% Tween 20 in PBS. Sections were then incubated at $4^{\circ} \mathrm{C}$ overnight with CD34 rat monoclonal antibody (Santa Cruz, cat \#sc-52478, stored at $4^{\circ} \mathrm{C}$ ). Next, slides were incubated for 1 hour with 7.5 $\mu \mathrm{g} / \mathrm{ml}$ biotinylated secondary antibody solution (1:200 dilution) at RT (Rabbit anti-rat IgG $(\mathrm{H}+\mathrm{L}), 1.5 \mathrm{mg} / \mathrm{ml}$ from VECTOR). Slides were then treated for 30 minutes with VECTASTAIN ABC followed by VIP staining. Counterstaining was preformed with pre-heated methyl green for 5 minutes. Lastly, slides were dehydrated and cleared for visual inspection.

\section{Murine CD135 Immunohistochemistry with VIP}

Prepared paraffin sections were heated in a $56^{\circ} \mathrm{C}$ oven for 90 minutes prior to hydration. Deparaffinization and hydration was accomplished with histoclear, ethanol and distilled water. Endogenous peroxides were quenched using 3\% hydrogen peroxide in methanol. Samples were then treated with antigen retrieval using a $10 \mathrm{mM}$ Citrate buffer by heating samples for 7 minutes in a microwave, followed by a 20-minute room air-cooling. Next, samples were blocked for 180 minutes with M.O.M Mouse Ig Blocking Reagent. Sections were then incubated at $4^{\circ} \mathrm{C}$ overnight with anti mouse Flt-3/Flk-2/CD135 monoclonal antibody (R\&D, cat\#MAB7681 stored at $\left.-20^{\circ} \mathrm{C}\right)$. Next, slides were incubated 
for 10 minutes with M.O.M.Biotinylated anti-mouse IgG with $10 \mu$ l of stock solution to 2.5ml of M.O.M. diluent. Slides were then treated for 30 minutes with VECTASTAIN ABC followed by VIP staining. Counterstaining was preformed with pre-heated methyl green for 5 minutes. Lastly, slides were dehydrated and cleared for visual inspection

\section{Human Anti-K15 immunohistochemistry with VIP}

Prepared paraffin sections were heated in a $56^{\circ} \mathrm{C}$ oven for 90 minutes prior to hydration. Deparaffinization and hydration was accomplished with histoclear, ethanol and distilled water. Endogenous peroxides were quenched using 3\% hydrogen peroxide in methanol. Samples were then treated with antigen retrieval using a $10 \mathrm{mM}$ Citrate buffer by heating samples for 7 minutes in a microwave, followed by a 20 minute room air cooling. Next, samples were blocked for 60 minutes with $5 \%$ normal goat serum, $1 \%$ BSA, $0.05 \%$

Tween 20 in PBS. Sections were then incubated at $4^{\circ} \mathrm{C}$ overnight with primary chicken anti-K15 polyclonal antibody (from COVANCE, cat\# PCK-153P, stored at $-20^{\circ} \mathrm{C}$ ). Next, slides were incubated for 1 hour with $7.5 \mu \mathrm{g} / \mathrm{ml}$ biotinylated secondary antibody solution (1:200 dilution) at RT (Goat anti-Chicken IgG $(\mathrm{H}+\mathrm{L}), 1.5 \mathrm{mg} / \mathrm{ml}$ from VECTOR). Slides were then treated for 30 minutes with VECTASTAIN ABC followed by VIP staining. Counterstaining was preformed with pre-heated methyl green for 5 minutes. Lastly, slides were dehydrated and cleared for visual inspection.

\section{Human CD34 immunohistochemistry with DAB}

Prepared paraffin sections were heated in a $56^{\circ} \mathrm{C}$ oven for 90 minutes prior to hydration. Deparaffinization and hydration was accomplished with histoclear, ethanol and distilled water. Endogenous peroxides were quenched using 3\% hydrogen peroxide in methanol. Samples were then treated with antigen retrieval using a 10mM Citrate buffer by heating 
samples for 7 minutes in a microwave, followed by a 20-minute room air-cooling. Next, samples were blocked for 60 minutes with 5\% normal hourse serum, 1\% BSA, 0.05\% Tween 20 in PBS. Sections were then incubated at $4^{\circ} \mathrm{C}$ overnight with anti-human CD34 mouse monoclonal antibody (BioGenex, cat\# MU236-UC, stored at $4^{\circ} \mathrm{C}$ ). Next, slides were incubated for 1 hour with $7.5 \mu \mathrm{g} / \mathrm{ml}$ biotinylated secondary antibody solution (1:200 dilution) at RT (Horse anti-mouse IgG $(\mathrm{H}+\mathrm{L}), 1.5 \mathrm{mg} / \mathrm{ml}$ from VECTOR). Slides were then treated for 30 minutes with VECTASTAIN ABC followed by DAB staining. Counterstaining was preformed with pre-heated methyl green for 5 minutes. Lastly, slides were dehydrated and cleared for visual inspection

\section{Human CD133 immunohistochemistry with DAB}

Prepared paraffin sections were heated in a $56^{\circ} \mathrm{C}$ oven for 90 minutes prior to hydration. Deparaffinization and hydration was accomplished with histoclear, ethanol and distilled water. Endogenous peroxides were quenched using $3 \%$ hydrogen peroxide in methanol. Samples were then treated with antigen retrieval using a $10 \mathrm{mM}$ Citrate buffer by heating samples for 7 minutes in a microwave, followed by a 20-minute room air-cooling. Next, samples were blocked for 60 minutes with 5\% normal rabbit serum, 1\% BSA, 0.05\% Tween 20 in PBS. Sections were then incubated at $4^{\circ} \mathrm{C}$ overnight with CD 133 rabbit polyclonal antibody (from abcam, cat\# ab19898, stored at $4^{\circ} \mathrm{C}$ ). Next, slides were

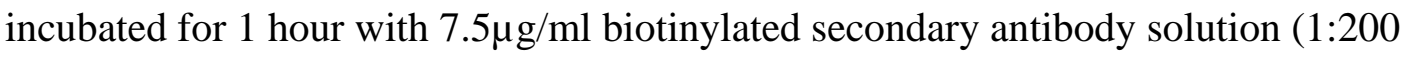
dilution) at RT (Goat anti-rabbit IgG $(\mathrm{H}+\mathrm{L}), 1.5 \mathrm{mg} / \mathrm{ml}$ from VECTOR). Slides were then treated for 30 minutes with VECTASTAIN ABC followed by DAB staining. Counterstaining was preformed with pre-heated methyl green for 5 minutes. Lastly, slides were dehydrated and cleared for visual inspection 


\section{Image Pro Analysis}

Quantitative analysis of both BrdU and K15 were used with subjective identification of the most active portion of the epidermis. Once identified, the epidermis was outlined using image pro plus software with 200x magnification for all specimens. The positively stained cells were highlighted and compared to the selected overall area of the epidermis as a quantitative percentage. 


\section{Chapter 3}

\section{Manuscript}

\section{Introduction}

To date, no studies have been conducted to identify stem cells or transient amplifying (TA) cells that reside in the oral cavity. Stem cell division creates two cell types, a memory daughter cell and a transient amplifying cell. TA cells, which are slightly more

differentiated than stem cells, serve as a reservoir for wound healing and homeostasis. ${ }^{1-3}$ Identification of either the stem cell or TA cell location(s) will provide a better understanding of normal and abnormal epithelial growth and tissue regeneration in the oral cavity.

Epidermal stem cells are located within the bulge zone of the associated hair follicles and not within the basal cell layer of the overlying epidermis. ${ }^{13-16}$ While it is generally accepted that the oral mucosal stem cells reside within the basal cell layer, due to ethical concerns regarding cell labeling, these findings have not been substantiated in humans. Skin wounds induce increased mitotic activity of bulge cells during wound repair. As the minor salivary glands of the oral mucosa represent an analogous specialized epithelial site, one of the stem cell pools of the oral mucosa may reside within salivary gland acini. 
Prior to the development of oral cancer, a premalignant lesion known as leukoplakia begins at the surface epithelium layer comprising ninety percent of oral cancer. The clinical component to these lesions is of great importance. Despite advances in surgical technique and skill, the recurrence rate of these lesions remains high. The histopathologic confirmation of surgically clear margins remains obsolete if lesions recur. Data strongly suggests that there is residual or sustained mutations within the stem cell pool that leads to these recurrences. As our purpose suggests, our ability to identify the existence of these stem cells will eventually lead to a target zone for chemotherapy.

The purpose of this study was to determine the location(s) of the oral mucosal stem cell pool(s). Identifying the oral stem cell pool could have a twofold purpose. First, these data would be of scientific interest from a biological perspective and secondly the precise localization of these cells can provide valuable clinical perspective for treatment modalities.

\section{Materials and Methods}

To address our question, we employed: 1) a murine oral mucosal wound healing model (wounding initiates stem cell proliferation), 2) human oral mucosal biopsies of ulcers overlying minor salivary glands. Immunohistochemical markers employed were: 1) K15 (primitive keratinocytes), 2) BrdU (thymidine analogue indicative of DNA synthesis), 3) CD34 (reported as an epidermal stem cell marker), 4) CD133 (hematopoietic and general stem markers). 


\subsection{Human Tissue Sampling}

K-15 preliminary studies were used in human tissue obtained from the Ohio State University Oral Pathology service (IRB protocol \#2007E0437). Human oral mucosa were obtained from the oral pathology service specific for ulcerated tissue of the buccal and vestibular mucosa. This tissue is known to have an abundance of minor salivary glands that undergo active wound healing. The use of K-15, a cytosolic keratin molecule will stain for less differentiated, quiescent cells. Initial findings to support the relationship between the integumentary system and oral cavity began with histological examination of human salivary gland tissue.

\subsection{Human Anti-K15 immunohistochemistry with VIP}

Prepared paraffin sections were heated in a $56^{\circ} \mathrm{C}$ oven for 90 minutes prior to hydration. Deparaffinization and hydration was accomplished with histoclear, ethanol and distilled water. Endogenous peroxides were quenched using $3 \%$ hydrogen peroxide in methanol. Samples were then treated with antigen retrieval using a 10mM Citrate buffer by heating samples for 7 minutes in a microwave, followed by a 20 minute room air cooling. Next, samples were blocked for 60 minutes with $5 \%$ normal goat serum, $1 \%$ BSA, $0.05 \%$

Tween 20 in PBS. Sections were then incubated at $4^{\circ} \mathrm{C}$ overnight with primary chicken anti-K15 polyclonal antibody (from COVANCE, cat\# PCK-153P, stored at $-20^{\circ} \mathrm{C}$ ). Next, slides were incubated for 1 hour with $7.5 \mu \mathrm{g} / \mathrm{ml}$ biotinylated secondary antibody solution (1:200 dilution) at RT (Goat anti-Chicken IgG $(\mathrm{H}+\mathrm{L}), 1.5 \mathrm{mg} / \mathrm{ml}$ from VECTOR). Slides were then treated for 30 minutes with VECTASTAIN ABC followed by VIP staining. Counterstaining was preformed with pre-heated methyl green for 5 minutes. Lastly, slides were dehydrated and cleared for visual inspection. 


\subsection{Human CD34 immunohistochemistry with $D A B$}

Prepared paraffin sections were heated in a $56^{\circ} \mathrm{C}$ oven for 90 minutes prior to hydration. Deparaffinization and hydration was accomplished with histoclear, ethanol and distilled water. Endogenous peroxides were quenched using $3 \%$ hydrogen peroxide in methanol. Samples were then treated with antigen retrieval using a $10 \mathrm{mM}$ Citrate buffer by heating samples for 7 minutes in a microwave, followed by a 20-minute room air-cooling. Next, samples were blocked for 60 minutes with 5\% normal horse serum, 1\% BSA, 0.05\% Tween 20 in PBS. Sections were then incubated at $4^{\circ} \mathrm{C}$ overnight with anti-human CD34 mouse monoclonal antibody (BioGenex, cat\# MU236-UC, stored at $4^{\circ} \mathrm{C}$ ). Next, slides were incubated for 1 hour with $7.5 \mu \mathrm{g} / \mathrm{ml}$ biotinylated secondary antibody solution (1:200 dilution) at RT (Horse anti-mouse IgG $(\mathrm{H}+\mathrm{L}), 1.5 \mathrm{mg} / \mathrm{ml}$ from VECTOR). Slides were then treated for 30 minutes with VECTASTAIN ABC followed by DAB staining. Counterstaining was preformed with pre-heated methyl green for 5 minutes. Lastly, slides were dehydrated and cleared for visual inspection

\subsection{Human CD133 immunohistochemistry with DAB (Abcam)}

Prepared paraffin sections were heated in a $56^{\circ} \mathrm{C}$ oven for 90 minutes prior to hydration. Deparaffinization and hydration was accomplished with histoclear, ethanol and distilled water. Endogenous peroxides were quenched using $3 \%$ hydrogen peroxide in methanol. Samples were then treated with antigen retrieval using a $10 \mathrm{mM}$ Citrate buffer by heating samples for 7 minutes in a microwave, followed by a 20-minute room air-cooling. Next, samples were blocked for 60 minutes with 5\% normal rabbit serum, 1\% BSA, 0.05\% Tween 20 in PBS. Sections were then incubated at $4^{\circ} \mathrm{C}$ overnight with CD 133 rabbit polyclonal antibody (from abcam, cat\# ab19898, stored at $4^{\circ} \mathrm{C}$ ). Next, slides were 


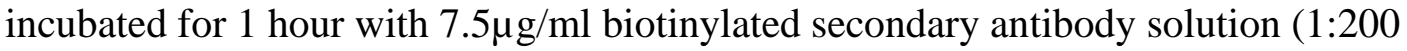
dilution) at RT (Goat anti-rabbit IgG $(\mathrm{H}+\mathrm{L}), 1.5 \mathrm{mg} / \mathrm{ml}$ from VECTOR). Slides were then treated for 30 minutes with VECTASTAIN ABC followed by DAB staining. Counterstaining was preformed with pre-heated methyl green for 5 minutes. Lastly, slides were dehydrated and cleared for visual inspection

\subsection{Murine Tissue Selection}

Murine protocol was in accordance with IACUC (Protocol \#2006A0174).

The goal to find the region of oral mucosa with the highest concentration of minor salivary glands was obtained using a murine model. Three FVB mice heads from a previous study was obtained and biopsied from various sites. Sampling of the soft/hard palate, ventral tongue, buccal mucosa and floor of the mouth was evaluated histologically to determine which area contained the highest amounts of minor salivary glands.

\subsection{Murine Model}

This model involves fifteen eight week old male FVB mice used over a six-day period. All mice were provided water and food access ad libitum and housed under a 12-hour dark and 12-hour light cycle. The fifteen mice were categorized in two separate groups. Ten in the experimental group and five in the control group. On day one, the experimental group was anestisized by intraperitoneal injection of ketamine $(40 \mathrm{mg} / \mathrm{kg})$ and Xylazine (10mg/kg). Once appropriate anesthesia was obtained, the experimental group was wounded. An experienced oral and maxillofacial surgeon using a dental implant drill performed the wounding. The tissue was wounded at the soft palate, slightly to the right of the midline and posterior to the vibrating line. Each wound was 
approximately $3 \times 3 \mathrm{~mm}$ in size. Next, All mice were injected with BrdU $(50 \mathrm{mg} / \mathrm{kg}$ IP at a concentration of $10 \mathrm{mg} / \mathrm{ml}$ in $0.9 \% \mathrm{NaCl}$ ).

The following day (day 2), all mice were injected with the same dose and concentration of BrdU. Three hours later, three mice (two experimental and one control) were euthanized and tissue samples were obtained as will be described. On day three, the remaining 12 mice were injected with a third dose of BrdU and three more mice (two experimental and one control) were euthanized and tissue sampled. This process will continue daily with all remaining mice receiving BrdU injections until euthanized (table $1)$.

\subsection{Murine Anti-Brdu immunohistochemistry}

Paraffin sections were heated in a $56^{\circ} \mathrm{C}$ oven for 90 minutes prior to hydration. Deparaffinization and hydration was accomplished with histoclear, ethanol and distilled water. Endogenous peroxides were quenched using $3 \%$ hydrogen peroxide in methanol. Samples were treated with trypsin(antigen masking) and incubated at $37^{\circ} \mathrm{C}$ for 30 minutes. Next, samples were blocked for 90 minutes with 5\% normal horse serum, $1 \%$ BSA, 0.05\% Tween 20 in PBS. Sections were then incubated at $4^{\circ} \mathrm{C}$ overnight with primary antibody anti-brdu VECTOR, cat VP-B209 with a dilution of 1:200. Slides were then Incubated 1 hour with $7.5 \mu \mathrm{g} / \mathrm{ml}$ biotinylated secondary antibody solution (1:200 dilution) at RT (Horse anti-mouse IgG $(\mathrm{H}+\mathrm{L})$ ). Slides were then treated for 30 minutes with VECTASTAIN ABC followed by DAB (Vector, cat\# SK-4100) staining for 5 minutes then counterstained with Hematoxylin QS for 1 minute. Lastly, slides were dehydrated and cleared for visual inspection.

\subsection{Murine Anti-K15 immunohistochemistry with VIP}


Prepared paraffin sections were heated in a $56^{\circ} \mathrm{C}$ oven for 90 minutes prior to hydration. Deparaffinization and hydration was accomplished with histoclear, ethanol and distilled water. Endogenous peroxides were quenched using $3 \%$ hydrogen peroxide in methanol. Samples were then treated with antigen retrieval using a 10mM Citrate buffer by heating samples for 7 minutes in a microwave, followed by a 20-minute room air-cooling. Next, samples were blocked for 60 minutes with $5 \%$ normal goat serum, $1 \%$ BSA, $0.05 \%$

Tween 20 in PBS. Sections were then incubated at $4^{\circ} \mathrm{C}$ overnight with primary chicken anti-K15 polyclonal antibody (from COVANCE, cat\# PCK-153P, stored at $-20^{\circ} \mathrm{C}$ ). Next, slides were incubated for 1 hour with $7.5 \mu \mathrm{g} / \mathrm{ml}$ biotinylated secondary antibody solution (1:200 dilution) at RT (Goat anti-Chicken IgG $(\mathrm{H}+\mathrm{L}), 1.5 \mathrm{mg} / \mathrm{ml}$ from VECTOR). Slides were then treated for 30 minutes with VECTASTAIN ABC followed by VIP staining. Counterstaining was preformed with pre-heated methyl green for 5 minutes. Lastly, slides were dehydrated and cleared for visual inspection.

\subsection{Murine CD34 Immunohistochemistry with VIP}

Prepared paraffin sections were heated in a $56^{\circ} \mathrm{C}$ oven for 90 minutes prior to hydration. Deparaffinization and hydration was accomplished with histoclear, ethanol and distilled water. Endogenous peroxides were quenched using 3\% hydrogen peroxide in methanol. Samples were then treated with antigen retrieval using a 10mM Citrate buffer by heating samples for 7 minutes in a microwave, followed by a 20-minute room air-cooling. Next, samples were blocked for 60 minutes with 5\% normal rabbit serum, 1\% BSA, 0.05\% Tween 20 in PBS. Sections were then incubated at $4^{\circ} \mathrm{C}$ overnight with CD34 rat monoclonal antibody (Santa Cruz, cat \#sc-52478, stored at $4^{\circ} \mathrm{C}$ ). Next, slides were incubated for 1 hour with $7.5 \mu \mathrm{g} / \mathrm{ml}$ biotinylated secondary antibody solution (1:200 
dilution) at RT (Rabbit anti-rat IgG $(\mathrm{H}+\mathrm{L}), 1.5 \mathrm{mg} / \mathrm{ml}$ from VECTOR). Slides were then treated for 30 minutes with VECTASTAIN ABC followed by VIP staining. Counterstaining was preformed with pre-heated methyl green for 5 minutes. Lastly, slides were dehydrated and cleared for visual inspection.

\subsection{Murine CD135 Immunohistochemistry with VIP}

Prepared paraffin sections were heated in a $56^{\circ} \mathrm{C}$ oven for 90 minutes prior to hydration. Deparaffinization and hydration was accomplished with histoclear, ethanol and distilled water. Endogenous peroxides were quenched using 3\% hydrogen peroxide in methanol. Samples were then treated with antigen retrieval using a 10mM Citrate buffer by heating samples for 7 minutes in a microwave, followed by a 20-minute room air-cooling. Next, samples were blocked for 180 minutes with M.O.M Mouse Ig Blocking Reagent.

Sections were then incubated at $4^{\circ} \mathrm{C}$ overnight with anti mouse Flt-3/Flk-2/CD135 monoclonal antibody (R\&D, cat\#MAB7681 stored at $\left.-20^{\circ} \mathrm{C}\right)$. Next, slides were incubated for 10 minutes with M.O.M.Biotinylated anti-mouse IgG with $10 \mu$ of stock solution to 2.5ml of M.O.M. diluent. Slides were then treated for 30 minutes with VECTASTAIN ABC followed by VIP staining. Counterstaining was preformed with pre-heated methyl green for 5 minutes. Lastly, slides were dehydrated and cleared for visual inspection

\subsection{Quantitative Image Analysis}

Quantitative analysis of both BrdU and K15 were used with subjective identification of the most active portion of the epidermis. Once identified, the epidermis was outlined using software techniques. The positively stained cells were highlighted and compared to the selected overall area of the epidermis as a quantitative percentage. 


\section{Results}

\subsection{Human K15 immunohistochemistry with VIP}

Immunohistochemistry demonstrated positive staining of K15 cells within the basal cell layer with obvious activity along the terminal ducts of minor salivary glands (Figure 2).

This activity was noted on multiple samples of human tissue containing a communication between epithelium and salivary gland ductal tissue.

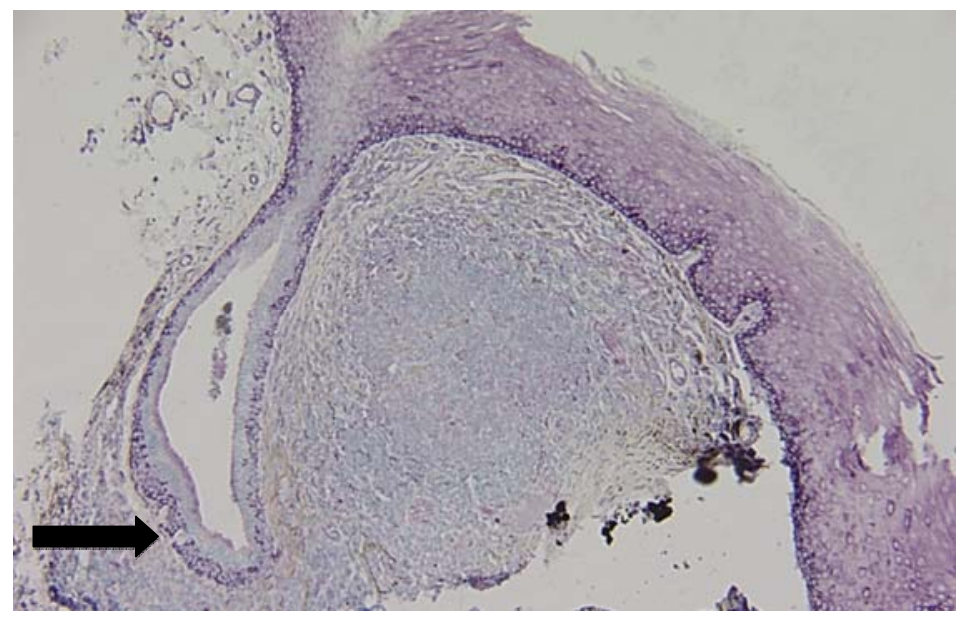

Figure 2: Human K15 immunohistochemistry with VIP

Human lower labial mucosa demonstrating terminal salivary duct interface with surface oral epithelium. K15 positive staining, indicative of primitive keratinocytes, is apparent in both basal keratinocytes as well as selected peripheral salivary duct keratinocytes. (100x image scale)

\subsection{Human CD34 immunohistochemistry with $D A B$}

Ulcerated mucoceles stained with CD 34 and DAB illustrated staining of endothelial cells within the connective tissue vasculature of multiple specimens (figure 3). VIP staining provided no substantial evidence for positive staining in both the epithelium and deeper connective tissues. 


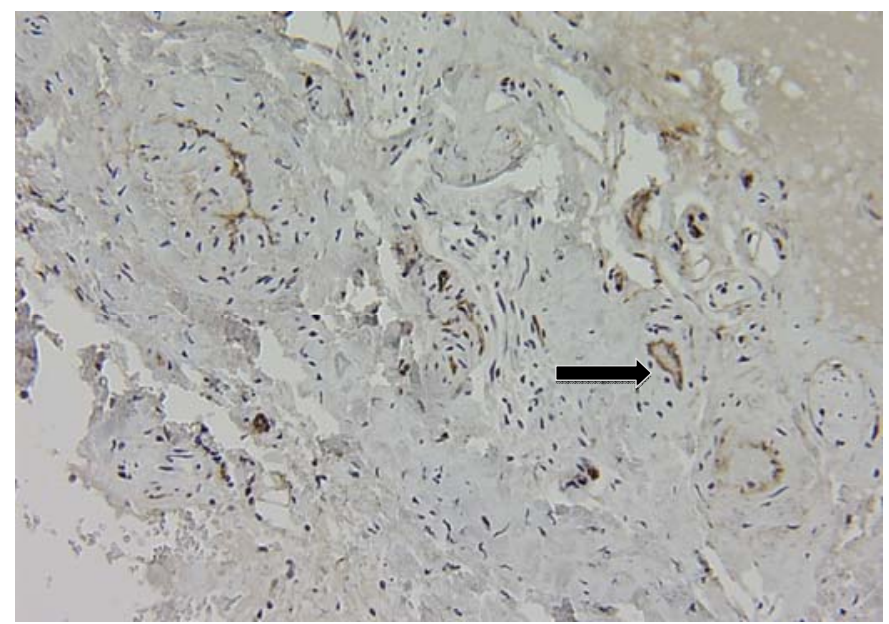

Figure 3: Human CD34 immunohistochemistry with $D A B$

CD34 staining highlighted the endothelial cells of the human connective tissue vasculature. (200x image scale)

\subsection{Human CD133 immunohistochemistry with $D A B$}

CD 133 displayed activity within salivary gland acinar structures of the ulcerated human mucosa using DAB. Attempts with VIP failed to highlight any positive cells during our staining protocol (figure 4). 


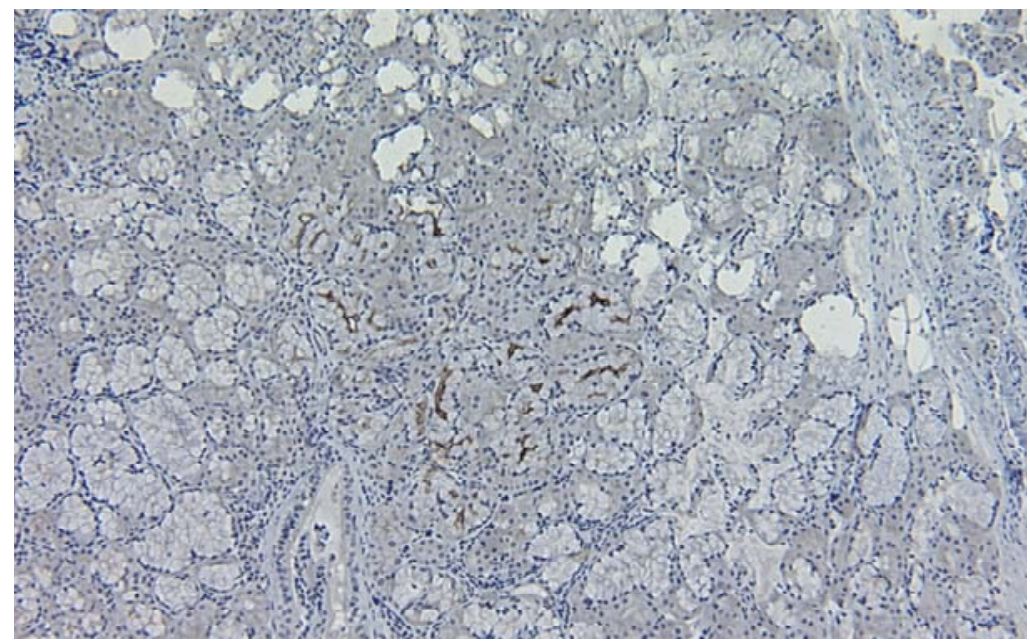

Figure 4: Human CD133 immunohistochemistry with $D A B$

Staining of human minor salivary gland tissue with putative stem cell marker CD133 reveals foci of positive staining within salivary gland acinar structures. (200x image scale)

\section{4. $\quad$ Murine Tissue Selection}

Routine histological review identified that the hard/soft palate junction of mice contain the highest concentration of minor salivary glands, followed by the floor of mouth, then buccal mucosa and finally the ventral tongue containing the fewest amounts of minor salivary glands. These findings were determined by routine H\&E staining protocols.

\subsection{Mouse Anti-Brdu immunohistochemistry}

Injured murine mucosa highlighted intense staining along the epithelium and connective tissue when compared to non-injured control mice. Increased activity along all the acinar of injured murine mucosa also induced more activity when compared to control murine mucosa (figure 5a and 5b). 


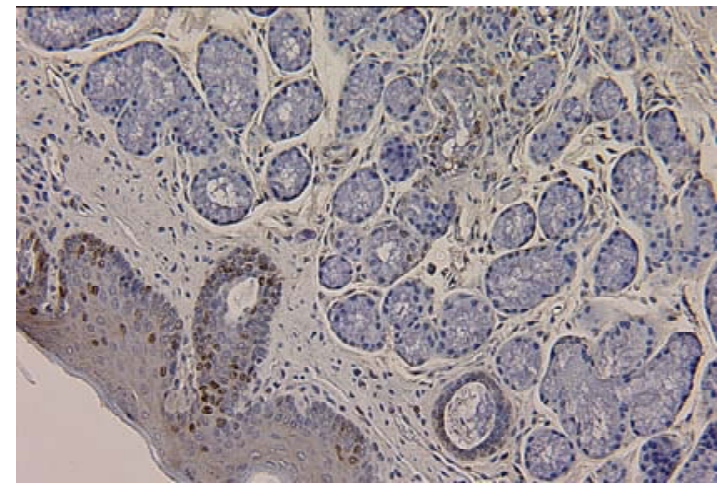

Figure 5a

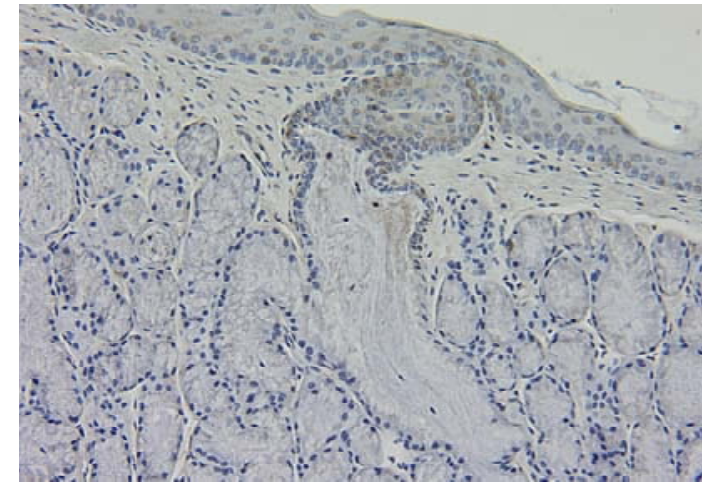

Figure $5 b$

5a. High proliferation index of wounded murine mucosa is reflected by intense BrdU positive staining of affected epithelium. 5b. In contrast, infrequent BrdU staining is apparent in non wounded control murine oral mucosa. (200x image scale)

\section{6. $\quad$ Mouse Anti-K15 immunohistochemistry with VIP}

Staining of K15 in the injured murine mucosa suggested increase activity along acini and epithelium of most mice. Non-injured mice also displayed staining of the epithelium with less activity along the salivary gland ductal tissues (figure 6). 


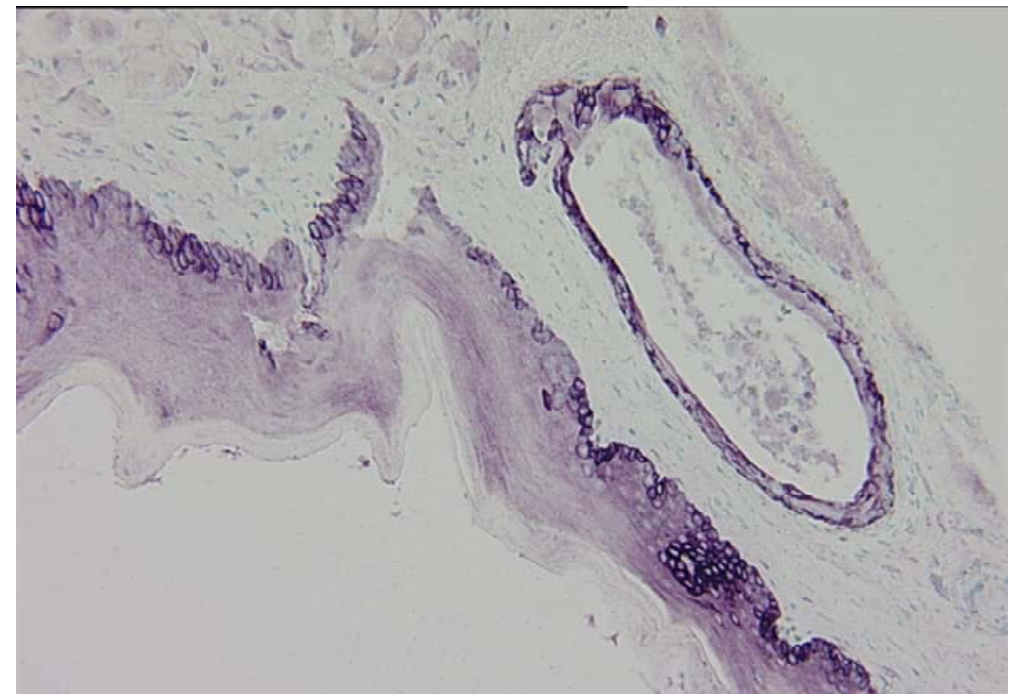

Figure 6: Mouse Anti-K15 immunohistochemistry with VIP

Analogous to human oral mucosa. Murine basal layer as well as salivary duct peripheral keratinocytes demonstrate positivity for the primitive keratinocyte marker K15. (200x image scale)

\section{7. $\quad$ Mouse CD34 Immunohistochemistry with VIP}

CD34 immunohisotchemistry illustrates equivocal findings in regards to primitive epithelial stem cells between injured and un-injured mice (figure 7). Both groups displayed large sensitivity to mast cell activity. 


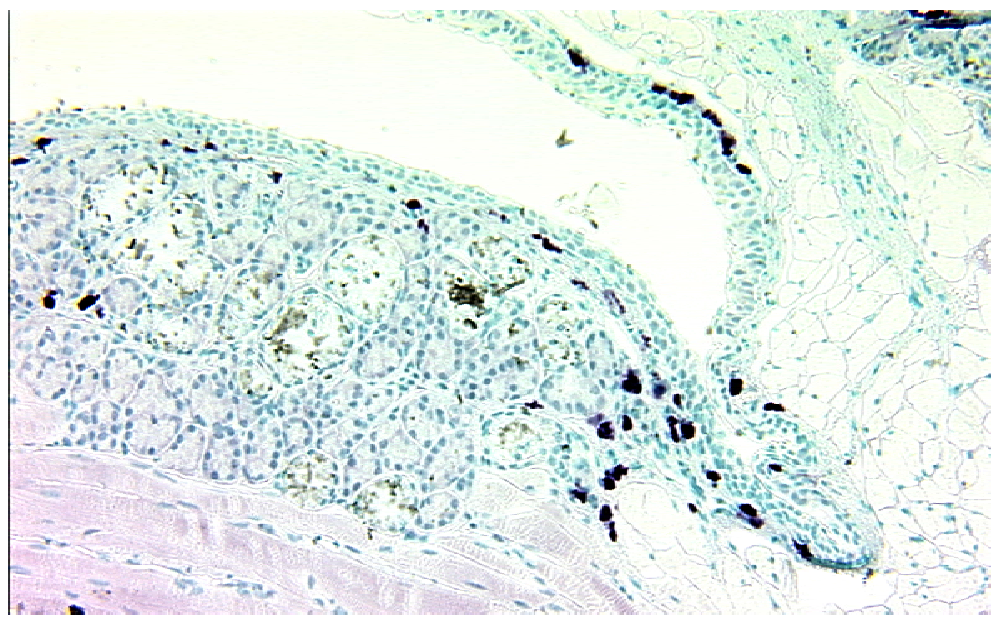

Figure 7: Mouse CD34 Immunohistochemistry

The nonspecificity of the putative stem cell marker CD34 is manifest by its reactivity with both primitive keratinocytes (previously identified as K15 positive) as well as mast cells in the underlying murine connective tissue. (200x image scale)

\subsection{Mouse CD135 Immunohistochemistry with VIP}

Many attempts were made to stain murine mucosa with CD135 but only background staining was obtained and no evidence of epithelial or endothelial staining was evident.

\subsection{Quantitative Image Analysis}

Image Pro software was used for evaluation methods of non-injured and injured mice stained with K15 and BrdU. Positive stained cells within the most active area of epithelium were isolated and compared to the entire surface area. Both K15 and BrdU showed higher activity along the epithelium and salivary ducts in the injured tissue when compared to the non-injured tissue (table 2). 


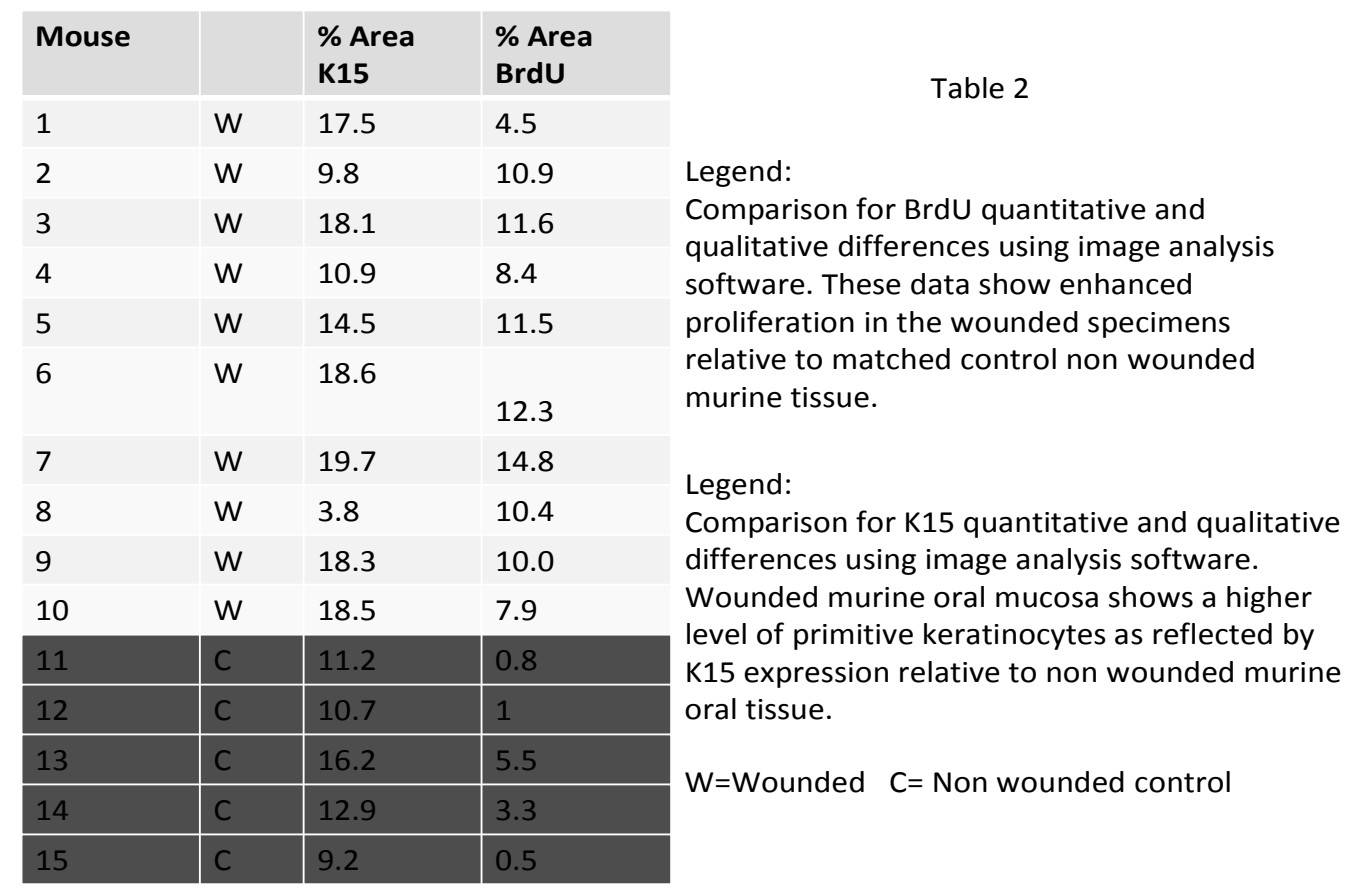

\section{Discussion}

\subsection{Human Tissue Staining}

The inability to employ in vivo cell labeling techniques to target actively replicating human cells requires alternate techniques to help identify actively dividing stem cells in human tissues. While, the analogy of the skin hair bulge to the mucosal salivary duct is feasible, no studies have attempted to compare these structures. We used similar dermatologic protocols to stain human mucosa that identified positive K15 staining along human ulcerated epithelium with involvement of the salivary acini. ${ }^{13-20}$ It is prudent to think that K15 alone would specify the location of TA cells because this marker highlights type I cytokeratin found in primitive progenitor basal cells and since oral mucosa is a highly active, self-renewing system that is under constant turnover, one would expect positive staining activity in both injured and non-injured tissues. ${ }^{4}$ During injury, the mucosa must call upon surrounding cells for wound healing, homeostasis and 
neoangiogenesis. The question remains, where do these cells originate? One would suspect they originate from bone marrow derived (BMD) stem cells. CD34 and CD133 stem cell markers have been identified in hematopoietic progenitor bone marrow stem cells, including systemic tumors, and isolated in hemangioendothelioblasts. ${ }^{28-33}$ The concept of hematopoietic derived disease has been established in a recent study involving dermatologic disease with kidney transplantation: Y chromosomes isolated from human female (male kidney donors) skin lesions is suggestive of hematopoietic connection with localized disease. ${ }^{39}$ Our present study demonstrated CD34 endothelial cell activity of ulcerated human mucosa within salivary gland connective tissue that indicated the possibility of hematopoietic involvement. CD133 has been used in many tissues for its unique structure and diverse staining ability. ${ }^{38-40}$ CD133 human stained tissue highlighted positive staining within a select group minor salivary gland acini contributing to more differentiated cells in wound healing and homeostasis. The concept of the most differentiated cells during wound healing must be derived from primitive stem cells. CD34 and CD133 positivity within the acinar structures represents primitive stem cell activity.

\subsection{Murine Tissue Staining}

The ability to track these cells from their origin creates difficult challenges since injecting humans and performing label-retaining studies is not ethical. An alternative was the development of a murine model to further exploration these findings.

The inability to stain human tissue with DNA incorporated stem cell markers led to the development of a murine model to identify actively replicating cells for localization of 
TA cells in the oral cavity. The use of BrdU systemic injections (Intrapertoneal) to track wound healing of murine mucosa illustrated favorable results in respect to wound healing and cellular activity. BrdU stains mitotically active cells during the S-phase of DNA synthesis and one would expect staining of normally active oral mucosa. The key finding with this marker was the increased activity in wounded mice but more specifically the increased activity along the salivary ducts. The use of BrdU is a key building block in identifying TA cells but not specific enough of a marker to localize primitive stem cells within acini. However, the ability of uptake of this marker into the oral cavity suggests promise for other potential markers. The use of K15 in the murine model demonstrated similar results as BrdU but with less intensity between injured and non-injured murine tissue as illustrated in Table 2. Activity along the ducts was clearly identified at a greater rate in the injured murine subjects with both markers.

To further probe the identification of the TA cell pool in the murine model we incorporated CD34, CD133 and CD135 staining. The use of CD34 reinforces previous studies of mast cell identification and provided minimal input for identification of the desired stem cell pool. ${ }^{33}$ CD133 and CD135 staining of the murine tissues displayed many challenges. Multiple attempts were made using different antibodies, block out agents and concentrations, but no results could be obtained from these markers in the murine model, which is consistent with previous attempts in mice. ${ }^{51}$ 


\section{Conclusion}

The current data imply that selected salivary gland acini are comparable to the bulge zone of the hair follicle and these cells contribute to the oral mucosal stem cell pool. Further, the localization of either of these cell pools may lead to advancements in cancer treatment and help direct chemoprevention. 


\section{Chapter 4}

\section{Conclusion}

The future of this study requires further specification of the TA pool of stem cells in the oral cavity in both the murine and human models. Recent literature suggests a promising marker that may provide more insight on TA cells location. Leucine-rich repeat-containing G-protein coupled receptor 5 (LGR5) has been expressed in ocular

limbal cells, intestinal epithelium and hair follicles using murine models and human specimens. $^{52-58}$

The ultimate goal is to identify the origin of the TA and stem cells that serve the oral cavity. The likely source as previously discussed is hematopoietic lineage. The next avenue to pursue includes label retaining stem cells that can be used in a murine model to identify and track TA cells from bone marrow to the oral cavity.

The current data imply that selected salivary gland acini are comparable to the bulge zone of the hair follicle and these cells contribute to the oral mucosal stem cell pool. Further, the localization of either of these cell pools may lead to advancements in cancer treatment and help direct chemoprevention. 


\section{References}

1. Vats A, Tolley N, Polak J, Buttery L. Stem cells: sources and applications. Clinical Otolaryngology 2002;27(4):227.

2. Cairns J. Somatic stem cells and the kinetics of mutagenesis and carcinogenesis. Proceedings of the National Academy of Sciences 2002;99(16):10567-10570.

3. Watt F, Hogan B. Out of Eden: stem cells and their niches. American Association for the Advancement of Science.Science 2000;287(5457):1427.

4. Dabelsteen S, Mackenzie I. The stem cell concept in the oral mucosa and in cancer. Den Norkske Tannlegeforenings Tidende 2006;116:32-36.

5. Silverman S,Jr, Gorsky M. Proliferative verrucous leukoplakia: a follow-up study of 54 cases. Oral Surg.Oral Med.Oral Pathol.Oral Radiol.Endod. 1997;84(2):154-157.

6. Casiglia J, Woo S. A comprehensive review of oral cancer. Gen.Dent. 2001;49(1):72.

7. Sciubba J. Oral cancer. The importance of early diagnosis and treatment. American Journal of Clinical Dermatology 2001;2(4):239.

8. Ishii J, Fujita K, Munemoto S, Komori T. Management of oral leukoplakia by laser surgery: relation between recurrence and malignant transformation and clinicopathological features. Journal of Clinical Laser Medicine and Surgery 2004;22(1):27.

9. Lippman S, Sudb, Ã, J, Hong WK. Oral cancer prevention and the evolution of molecular-targeted drug development. Journal of clinical oncology : official journal of the American Society of Clinical Oncology 2005;23(2):346-356.

10. Lumerman H, Freedman P, Kerpel S. Oral epithelial dysplasia and the development of invasive squamous cell carcinoma. Oral Surg.Oral Med.Oral Pathol.Oral Radiol.Endod. 1995;79(3):321-329.

11. Holmstrup P, Vedtofte P, Reibel J, Stoltze K. Long-term treatment outcome of oral premalignant lesions. Oral Oncol. 2006;42(5):461. 
12. Tran S, Pillemer S, Dutra A, Barrett A, Brownstein M, Key S, et al. Differentiation of human bone marrow-derived cells into buccal epithelial cells in vivo: a molecular analytical study. 2003;361(9363):1084.

13. Cotsarelis G, Sun T, Lavker R. Label-retaining cells reside in the bulge area of pilosebaceous unit: implications for follicular stem cells, hair cycle, and skin carcinogenesis. Cell (Cambridge) 1990;61(7):1329.

14. Lyle S, Christofidou-Solomidou M, Liu Y, Elder D, Albelda S, Cotsarelis G. The C8/144B monoclonal antibody recognizes cytokeratin 15 and defines the location of human hair follicle stem cells. J.Cell.Sci. 1998;111 ( Pt 21):3179.

15. Lyle S, Christofidou-Solomidou M, Liu Y, Elder D, Albelda S, Cotsarelis G. Human hair follicle bulge cells are biochemically distinct and possess an epithelial stem cell phenotype. The journal of investigative dermatology.Symposium proceedings / the Society for Investigative Dermatology, Inc.[and] European Society for Dermatological Research 1999;4(3):296.

16. Cotsarelis G. Epithelial stem cells: a folliculocentric view. The Journal of investigative dermatology. 2006;126(7):1459.

17. Whitbread L, Powell B. Expression of the intermediate filament keratin gene, K15, in the basal cell layers of epithelia and the hair follicle. Exp.Cell Res. 1998;244(2):448.

18. Jih D, Lyle S, Elenitsas R, Elder D, Cotsarelis G. Cytokeratin 15 expression in trichoepitheliomas and a subset of basal cell carcinomas suggests they originate from hair follicle stem cells. J.Cutan.Pathol. 1999;26(3):113.

19. Porter R, Lunny D, Ogden P, Morley S, McLean W, Evans A, et al. K15 expression implies lateral differentiation within stratified epithelial basal cells. 2000;80(11):1701.

20. Liu Y, Lyle S, Yang Z, Cotsarelis G. Keratin 15 promoter targets putative epithelial stem cells in the hair follicle bulge. The Journal of investigative dermatology. 2003;121(5):963.

21. Deng W, Han Q, Liao L, Li C, Ge W, Zhao Z, et al. Engrafted bone marrow-derived flk-(1+) mesenchymal stem cells regenerate skin tissue. Tissue Eng. 2005 Jan-Feb;11(12):110-119.

22. Ito M, Liu Y, Yang Z, Nguyen J, Liang F, Morris R, et al. Stem cells in the hair follicle bulge contribute to wound repair but not to homeostasis of the epidermis. Nat.Med. 2005;11(12):1351.

23. Kaur P. Interfollicular epidermal stem cells: identification, challenges, potential. The Journal of investigative dermatology. 2006;126(7):1450. 
24. Yoshida S, Shimmura S, Kawakita T, Miyashita H, Den S, Shimazaki J, et al. Cytokeratin 15 can be used to identify the limbal phenotype in normal and diseased ocular surfaces. Invest.Ophthalmol.Visual Sci. 2006;47(11):4780.

25. Zola H, Swart B, Nicholson I, Aasted B, Bensussan A, Boumsell L, et al. CD molecules 2005: human cell differentiation molecules. Blood 2005;106(9):3123.

26. Zola H. Medical applications of leukocyte surface molecules--the CD molecules. Mol.Med. 2006;12(11-12):312.

27. Zola H, Swart B, Banham A, Barry S, Beare A, Bensussan A, et al. CD molecules 2006--human cell differentiation molecules. J.Immunol.Methods 2007;319(1-2):1.

28. Krause D, Fackler M, Civin C, May W. CD34: structure, biology, and clinical utility. Blood 1996;87(1):1.

29. Drew E, Merkens H, Chelliah S, Doyonnas R, McNagny K. CD34 is a specific marker of mature murine mast cells. Exp.Hematol. 2002;30(10):1211.

30. Lathers D, Achille N, Young MR. Dendritic cell development from mobilized peripheral blood CD34 cells. Methods Mol.Biol. 2003;215:409-415.

31. Namikawa K, Takahashi T, Nakamura Y, Otsuka F. Cutaneous carcinosarcoma comprising basal cell carcinoma and CD34 fibrosarcoma. Journal of the European Academy of Dermatology and Venereology 2008;22(6):757.

32. Greaves M, Brown J, Molgaard H, Spurr N, Robertson D, Delia D, et al. Molecular features of CD34: a hemopoietic progenitor cell-associated molecule. Leukemia : official journal of the Leukemia Society of America, Leukemia Research Fund, U.K 1992;6 Suppl 1:31-36.

33. Perrella G, Brusini P, Spelat R, Hossain P, Hopkinson A, Dua H. Expression of haematopoietic stem cell markers, CD133 and CD34 on human corneal keratocytes. Br.J.Ophthalmol. 2007;91(1):94.

34. Mizrak D, Brittan M, Alison MR. CD133: molecule of the moment. 2008;214(1):3.

35. Yin A, Miraglia S, Zanjani E, Almeida-Porada G, Ogawa M, Leary A, et al. AC133, a novel marker for human hematopoietic stem and progenitor cells. Blood 1997;90(12):5002.

36. Yu Y, Flint A, Dvorin E, Bischoff J. AC133-2, a novel isoform of human AC133 stem cell antigen. The Journal of biological chemistry. 2002;277(23):20711.

37. Shmelkov S, St Clair R, Lyden D, Rafii S. AC133/CD133/Prominin-1. Int.J.Biochem. 2005;37(4):715. 
38. Richardson G, Robson C, Lang S, Neal D, Maitland N, Collins A. CD133, a novel marker for human prostatic epithelial stem cells. J.Cell.Sci. 2004;117(Pt 16):3539.

39. LaBarge M, Bissell MJ. Is CD133 a marker of metastatic colon cancer stem cells? 2008;118(6):2021.

40. Smith L, Nesterova A, Ryan M, Duniho S, Jonas M, Anderson M, et al. CD133/prominin-1 is a potential therapeutic target for antibody-drug conjugates in hepatocellular and gastric cancers. Br.J.Cancer 2008;99(1):100.

41. Drexler H, Meyer C, Quentmeier H. Effects of FLT3 ligand on proliferation and survival of myeloid leukemia cells. Leukemia 1999;33(1-2):83-91.

42. Brasel K, Escobar S, Anderberg R, de Vries P, Gruss H, Lyman S. Expression of the flt3 receptor and its ligand on hematopoietic cells. Leukemia : official journal of the Leukemia Society of America, Leukemia Research Fund, U.K 1995;9(7):1212-1218.

43. Rosnet O, B, Ã¹/4hring H, deLapeyri, Ã“re O, Beslu N, et al. Expression and signal transduction of the FLT3 tyrosine kinase receptor. Acta Haematol. 1996;95(3-4):218-223.

44. Tudor D, Locke M, Owen-Jones E, Mackenzie I. Intrinsic patterns of behavior of epithelial stem cells. The journal of investigative dermatology.Symposium proceedings / the Society for Investigative Dermatology, Inc.[and] European Society for Dermatological Research 2004;9(3):208.

45. Snyder B, Olanow C. Stem cell treatment for Parkinson's disease: an update for 2005. Curr.Opin.Neurol. 2005;18(4):376.

46. Trzaska K, Rameshwar P. Current advances in the treatment of Parkinson's disease with stem cells. Current Neurovascular Research 2007;4(2):99.

47. Malm T, Koistinaho M, Parepalo M, Vatanen T, Ooka A, Karlsson S, et al. Bonemarrow-derived cells contribute to the recruitment of microglial cells in response to betaamyloid deposition in APP/PS1 double transgenic Alzheimer mice. Neurobiol.Dis. 2005;18(1):134.

48. Houghton J, Stoicov C, Nomura S, Rogers A, Carlson J, Li H, et al. Gastric cancer originating from bone marrow-derived cells. American Association for the Advancement of Science.Science 2004;306(5701):1568.

49. Aractingi S, Kanitakis J, Euvrard S, Le Danff C, Peguillet I, Khosrotehrani K, et al. Skin carcinoma arising from donor cells in a kidney transplant recipient. 2005;65(5):1755. 
50. Markovic-Lipkovski J, Muller C, Klein G, Flad T, Klatt T, Blaschke S, et al. Neural cell adhesion molecule expression on renal interstitial cells. Nephrology, dialysis, transplantation : official publication of the European Dialysis and Transplant Association - European Renal Association 2007;22(6):1558.

51. Mestas J, Hughes CC. Of mice and not men: differences between mouse and human immunology. Journal of immunology (Baltimore, Md.: 1950) 2004;172(5):2731-2738.

52. Barker N, van Es J, Kuipers J, Kujala P, van dB, Cozijnsen M, et al. Identification of stem cells in small intestine and colon by marker gene Lgr5. Nature (London) 2007;449(7165):1003-1007.

53. Becker L, Huang Q, Mashimo H. Immunostaining of Lgr5, an intestinal stem cell marker, in normal and premalignant human gastrointestinal tissue. ScientificWorldJournal 2008;8:1168-1176.

54. Majo F, Rochat A, Nicolas M, Jaoud, Ã $\odot$ G, Barrandon Y. Oligopotent stem cells are distributed throughout the mammalian ocular surface. Nature (London) 2008;456(7219):250-254.

55. Haegebarth A, Clevers H. Wnt signaling, lgr5, and stem cells in the intestine and skin. Am.J.Pathol. 2009;174(3):715-721.

56. Barker N, Huch M, Kujala P, van dW, Snippert H, van Es J, et al. Lgr5( ve) stem cells drive self-renewal in the stomach and build long-lived gastric units in vitro. Cell Stem Cell 2010;6(1):25-36.

57. Fan X, Wu H, Yu H, Zhou Q, Zhang Y, Huang Q. Expression of Lgr5 in human colorectal carcinogenesis and its potential correlation with beta-catenin. Int.J.Colorectal Dis. 2010;25(5):583-590.

58. Snippert H, Haegebarth A, Kasper M, Jaks V, van Es J, Barker N, et al. Lgr6 marks stem cells in the hair follicle that generate all cell lineages of the skin. Science (New York, N.Y.) 2010;327(5971):1385-1389. 